\title{
ADOLESCENTES EM SITUAÇÃO DE RUA: PROSTITUIÇÃO, DROGAS E HIV/AIDS EM SANTO ANDRÉ, BRASIL
}

\author{
Eliane Lima Guerra Nunes e Arthur Guerra de Andrade \\ Faculdade de Medicina do ABC, Santo André, Brasil
}

\begin{abstract}
RESUMO: O objetivo do estudo foi investigar as condições de vida de adolescentes do sexo feminino em situação de rua, envolvidas com o abuso de drogas e com a prostituição, visando orientar estratégias de prevenção às Doenças Sexualmente Transmissíveis - DST/AIDS. Foram entrevistadas sete adolescentes entre 14 e 19 anos, por meio de roteiro semi-estruturado com questões sobre escolaridade; desligamento da família; violência; histórico de uso de drogas, sexualidade e existência de DST/AIDS; vida na rua e futuro. Observou-se que os principais motivos que levaram essas adolescentes à rua foram violência doméstica; baixo nível sócio-econômico familiar e abuso de múltiplas drogas. As entrevistadas afirmaram conhecer medidas preventivas para as DST/AIDS, porém não as aplicaram aos clientes fixos e namorados. A análise dos resultados obtidos nesta pesquisa confirma a importância da criação de estratégias específicas para as DST/AIDS, além da adequação da rede educacional e de atenção psicossocial às necessidades das adolescentes para a garantia de seus direitos e conquista da emancipação.
\end{abstract}

PALAVRAS-CHAVE: adolescência; violência doméstica; abuso de drogas; prostituição; AIDS.

\section{STREET YOUTH: PROSTITUTION, DRUGS AND HIV/AIDS IN SANTO ANDRÉ-BRAZIL}

ABSTRACT: The aim of this study was to investigate living conditions of female street adolescents, who are involved with illicit and licit drugs, and with prostitution, in the city of Santo André, as well as to tailor strategies for STD/AIDS prevention. We have interviewed seven adolescents, aged from 14 to 19 years old, using a semi-structured questionnaire with questions about education, family disaffection, violence, living on the streets, history of drug use, sexuality, level of information about STD/AIDS, and hopes for the future. We observed that among the reasons for these adolescents to live on the streets were domestic violence, low socioeconomic level, and drug abuse. They stated that they are aware of STD/AIDS preventive measures, but they do not bring them into effect with steady partners and boyfriends. The analysis of our results confirms the importance of creating well-defined strategies to STD/AIDS prevention, additionally to suitable educational system and psychosocial attention service. This will assure adolescents' rights and emancipation.

KEYWORDS: adolescence; domestic violence; drug abuse; prostitution; AIDS.

\section{Introdução}

Os adolescentes representam mais de um quarto da população mundial e, em sua maioria (87\%), vivem em países em desenvolvimento. São vulneráveis às doenças sexualmente transmissíveis (DST) e à síndrome da imunodeficiência adquirida (AIDS), principalmente os que sofrem violência e exploração sexual e vivem abaixo da linha da pobreza (Joint United Nations Programme on HIV/AIDS [UNAIDS], 2008; Krug, Fdahlberg, Mercy, Zwi, \& Lozano, 2002; Pinheiro, 2006).

Segundo o Ministério da Saúde do Brasil (Brasil, 2005), a proporção de adolescentes entre 13 e 19 anos de cada sexo com HIV até o ano de 1997 era de $1: 1$, porém no ano de 2005 houve predomínio do sexo feminino, de 1: 1,77.

$\mathrm{O}$ uso de preservativos no primeiro intercurso sexual cresceu de $10 \%$, em 1986, para mais de $60 \%$ em 2003 (Brasil, 2005), porém a diferença do nível socioeconômico é importante fator na disseminação das DST/AIDS, pois, segundo Moura, Harpham e Lyons (2003), os adolescentes que não estão inseridos nas escolas são mais suscetíveis de adotar comportamento de risco, uma vez que detêm mais mitos em relação à infecção pelo HIV/AIDS, além de terem dificuldade de mudar suas crenças devido a informações reduzidas ou deturpadas sobre a mesma.

A prevalência de HIV/AIDS no Brasil é inferior a 1\%. Embora a incidência tenha diminuído de 18:100.000 habitantes em 2006 (Brasil, 2006) para 17,5:100.000 habitantes em 2007 (Brasil, 2007), as tendências atuais da epidemia indicam uma mudança em seu perfil, com um crescimento acelerado em populações mais vulneráveis, como mulheres e pobres, e um decréscimo entre homens e usuários de drogas - UD. A mudança que ocorreu no perfil da epidemia requer novas abordagens em relação 
à prevenção e ao controle, além de ações diferenciadas para cada público em que ela se desenvolve mais pronunciadamente, como as populações empobrecidas (Brito, Castilho, \& Szwarcwald, 2000).

Os adolescentes que estão em situação de rua e em vários bolsões de pobreza tornam-se mais vulneráveis às doenças sexualmente transmissíveis - DST/AIDS devido a vários fatores, como o uso e abuso de drogas lícitas (álcool, tabaco) e ilícitas (solventes, maconha, cocaína e seus derivados, entre outros), relações sexuais desprotegidas, dificuldade para aquisição dos preservativos, violência doméstica e exploração sexual comercial, entre outros (Raffaelli et al., 1993; Noto et al., 2004; De Carvalho, Neiva-Silva, Ramos, Koller, \& Page Shafer, 2006).

Em um levantamento nacional sobre o uso de drogas em 27 capitais brasileiras, realizado com 2087 crianças e adolescentes em situação de rua, apontou-se a necessidade de medidas efetivas, pois há associação entre o consumo de álcool, o uso de drogas ilícitas e o sexo sem preservativos. Na região sudeste, o padrão de consumo encontrado foi de $40,1 \%$ para maconha, $39,9 \%$ para solventes, $38,4 \%$ para álcool e 26,2\% para cocaína e seus derivados. Na capital paulista, foram entrevistadas 42 crianças e adolescentes, sendo que, desses, $92,9 \%$ revelaram que não moravam com a família e $90,5 \%$ faziam uso diário de múltiplas drogas (vinte dias ou mais), sendo 54,8\% para solventes, $47,6 \%$ para maconha, $9,5 \%$ para cocaína e seus derivados e 7,1\% para álcool (Noto et al., 2004).

Em estudo realizado na cidade de Porto Alegre com 161 crianças e adolescentes em situação de rua, atendidos apenas em instituições que permitiam o ingresso conforme o desejo dos interessados e não exigiam a saída da rua, constatou-se um padrão de consumo de drogas ilícitas, nos últimos 12 meses, de $39,7 \%$, sendo que $4,2 \%$ dos participantes referiram o uso de maconha, $31,7 \%$ de solventes, $19,9 \%$ de cocaína ou crack e 1,2\% o uso de cocaína injetável. Quanto ao uso de drogas lícitas, 83,8\% referiram consumo de álcool e 48,2\% de tabaco (De Carvalho et al., 2006). Na amostra estudada, observou-se que $33,7 \%$ daqueles que mantiveram relações sexuais desprotegidas relataram tê-lo feito sob os efeitos do uso de drogas. $\mathrm{Na}$ amostra pesquisada, $41,0 \%$ fizeram teste para o HIV, sendo $9,1 \%$ soropositivos. Os autores salientam que $37,9 \%$ dos entrevistados acreditavam que não iriam contrair o HIV e indicam a necessidade da oferta de uma rede de serviços preparados para esse público: alimentação, educação, esporte, atividades artísticas, assistência à saúde e abrigo que, em regra, colaboram para uma aderência maior ao tratamento, diminuindo o tempo de exposição nas ruas e, consequentemente, a vulnerabilidade às DST/AIDS, além de apontarem a importância de uma abordagem mais adequada na prevenção das DST/HIV associadas ao uso de drogas.
O estudo de Nappo et al. (2004), com 75 mulheres envolvidas com o sexo comercial em São Paulo e São José do Rio Preto, revela que $23 \%$ possuíam menos de 20 anos e que as que estavam envolvidas com o uso de drogas ilícitas, em especial o crack, colocavam-se em situações de maior vulnerabilidade e apresentavam maior dificuldade para se proteger das DST/AIDS por meio do uso de preservativos.

Segundo Simon (1999), em estudo realizado em Ribeirão Preto, com 13 jovens envolvidas com a prostituição, embora elas demonstrassem conhecimento sobre medidas preventivas contra o HIV/AIDS, não as praticavam, pois acreditavam na predestinação como fator determinante para a infecção pelo HIV/AIDS, além de buscar afetividade nos relacionamentos.

As políticas de Saúde Pública precisam ajustarse à realidade das adolescentes em situação de rua e suas famílias, conforme apontam os estudos citados anteriormente, pois, apesar de elas exibirem uma importante resiliência, ou seja, uma elevada capacidade de lidar com as dificuldades através da criatividade e da inteligência, entre outros atributos, terão dificuldade para sair da rua sem suporte adequado (Gomes, 1994; Paludo \& Koller, 2005).

\section{Objetivo}

O presente estudo objetivou conhecer melhor a realidade de adolescentes em situação de rua envolvidas com a exploração sexual comercial para discutir aspectos que possam servir como subsídio para melhorar o entendimento dessa realidade e, assim, orientar as estratégias para diminuir a vulnerabilidade às DST/AIDS.

\section{Métodos}

Foi realizada, entre dezembro de 2003 e janeiro de 2004, na cidade de Santo André, Brasil, uma pesquisa de cunho qualitativo com adolescentes entre 14 e 19 anos, em situação de rua, envolvidas com a exploração sexual comercial.

Durante os seis meses anteriores às entrevistas, a pesquisadora fez uma observação de campo no período noturno em locais onde a prostituição adulta era notória na cidade, fato indicado tanto pelos conselhos tutelares quanto em cobertura jornalística (Angrimani, 2003). Esse levantamento foi efetuado em algumas das visitas para a implantação, em parceria com a Comunidade Europeia, do projeto de Redução de Danos em Mulheres Dependentes Químicas (Comunidade Europeia, 2008). Dois técnicos faziam a abordagem das profissionais do sexo que fossem receptivas para receber preservativos e informações sobre as DST/AIDS, encaminhando as à 
rede pública e para que a pesquisadora pudesse conversar com as adolescentes e agendar uma entrevista.

As jovens menores de idade relataram receio de serem descobertas pela polícia. Duas jovens, de 19 e de 20 anos, moradoras de rua, usuárias de drogas e que estavam envolvidas com o comércio sexual, foram receptivas ao convite da pesquisadora e passaram a ser identificadas como informantes-chave. Elas informaram os horários e locais mais frequentados por outras adolescentes e encaminharam duas jovens para a entrevista com a pesquisadora, o que permitiu a descoberta de duas redes de adolescentes: as que viviam na Av. Industrial e as do Bairro Sacadura Cabral, além de fornecerem elementos para a elaboração do roteiro da entrevista.

A entrevista aberta, com um roteiro semi-estruturado, assim como outros procedimentos metodológicos, baseou-se nos pressupostos das pesquisas qualitativas (Bardin, 1977) e, naquelas anteriormente realizadas com a mesma população (Gomes, 1994, 1996; Nappo et al., 2004; Simon, 1999).

Adotaram-se como critérios de inclusão: ser do sexo feminino, viver na rua há mais de um ano, ter entre 12 e 19 anos, ser usuária de drogas lícitas ou ilícitas por no mínimo um ano, estar envolvida com a prostituição há pelo menos um ano, participar da coleta de exames, aceitar participar da pesquisa e assinar o Termo de Consentimento Livre e Esclarecido- TCLE.

Foram realizadas pela pesquisadora entrevistas individuais semidirigidas, com questões sobre: escolaridade, família, desligamento da família, vida na rua, violência, cultura de sobrevivência, histórico do uso de drogas, sexualidade, conhecimento de risco às DST/ AIDS e expectativas de futuro.

As adolescentes foram convidadas para um segundo encontro, durante o dia, no qual poderiam esclarecer as suas dúvidas e ser orientadas. Em seguida, foram acompanhadas ao Centro de Orientação e Apoio Sorológico (COAS) de Santo André para a coleta de exames laboratoriais: sorologia de HIV1/HIV2 (teste rápido, imunocaptura de anticorpos, Elisa-enzima imunoensaio e imunofluorescência indireta); sífilis (VDRL e FTA-ABS); gonorreia e hepatites $\mathrm{B}$ e $\mathrm{C}$ (método E.I.A. - enzyme immunoassay). Procedeu-se aconselhamento pré e pós-testes e os resultados foram entregues às participantes. Aquelas que apresentaram resultados positivos foram encaminhadas para tratamento, porém apenas uma compareceu ao ambulatório de referência (E2), apesar de não ter retornado para seguimento.

Todas as entrevistas foram realizadas no período noturno, em um centro comunitário próximo a um dos locais de comércio sexual frequentados pelas adolescentes (Vila Sacadura Cabral), com duração entre 30 e 50 minutos. As entrevistas, gravadas com o consentimento das adolescentes, foram transcritas para serem analisadas segundo as normas para textos orais (Bardin, 1977).

Para a análise e tratamento do material, adotamos a proposta de Minayo (1994), que leva em consideração dois níveis de interpretação inter-relacionados: um referente ao contexto sócio-histórico estabelecido na fase exploratória da pesquisa e o outro resultante do entrecruzamento das diversas entrevistas e da observação participante.

$\mathrm{Na}$ primeira etapa, realizou-se uma leitura flutuante das entrevistas para análise do conteúdo temático (Bardin, 1977). Em seguida, passou-se a uma leitura exaustiva das transcrições, buscando-se identificar os temas que, por sua frequência, e também por sua relevância, trouxeram significado para a pesquisa proposta.

$\mathrm{Na}$ análise e interpretação, buscou-se descrever os resultados mais significativos, oriundos da comparação dos dados encontrados nas entrevistas, na pesquisa de campo e aqueles que se assemelham aos achados por outros autores (Gomes, 1996; Minayo, 1994; Minayo \& Souza, 2003; Spink, 2000), chegando-se às conclusões mais relevantes e pertinentes à proposta da pesquisa.

As principais temáticas identificadas foram: a violência na família e na rua, nas relações estabelecidas com outras jovens e principalmente com os clientes; a exploração sexual comercial como fonte de renda e manutenção do consumo de drogas; e sua sexualidade, expressa nas relações afetivas com namorados e clientes fixos, bem como o desejo de ter filhos e o ideário sobre as DST/AIDS. Os resultados serão apresentados neste artigo através da exposição dos recortes mais expressivos dos discursos das adolescentes, que permitam nortear algumas inferências úteis para que estratégias preventivas e de assistência possam ser delineadas.

O projeto de pesquisa foi aprovado pelo Comitê de Ética e Pesquisa - CEP da Faculdade de Medicina da Universidade de São Paulo, assim como pelo Conselho de Direito da Criança e do Adolescente da cidade de Santo André, conforme preconiza o Estatuto da Criança e do Adolescente - ECA/1990 (Brasil, 1990).

\section{Resultados}

Foram encontradas, durante o período da pesquisa, entre dezembro de 2003 e janeiro de 2004, dez adolescentes que estavam dentro dos critérios de inclusão, porém somente sete participaram. Duas negaram a participação e uma foi excluída pelo critério de idade.

Durante os seis meses que antecederam a pesquisa, por ocasião do trabalho de campo, foram identificadas dezesseis adolescentes que atenderiam aos critérios acima, no entanto seis não foram encontradas no período pesquisado.

Todas as adolescentes são oriundas de famílias com precária situação socioeconômica, com renda infe- 
rior a $1 / 2$ salário mínimo per capita. Apenas uma família, a de E2, foi possível ser contatada e acompanhada pela pesquisadora, a pedido da mãe, que solicitou atendimento para ela e para uma outra filha de 8 anos.

Todas estavam fora dos programas assistenciais e de saúde disponíveis na cidade, apesar de referirem atendimento anterior por algumas das instituições de saúde e assistência social como: o Centro de Atenção Psicossocial para Álcool e Drogas - CAPS-AD, serviços de saúde de urgência como o Pronto-Socorro - PS, a Casa de Acolhida, o Conselho Tutelar e educadores sociais de rua do Programa Andrezinho Cidadão. Todas alegaram que os serviços de saúde e ação social não eram acessíveis, devido a fatores como: horário de funcionamento incompatível com o estilo de vida e regras de inclusão.

É importante ressaltar a diferença entre as entrevistadas nos quesitos tempo de vida na rua e tempo de envolvimento com o comércio sexual.
As adolescentes não frequentavam nenhuma instituição de ensino e possuíam baixa escolaridade (média de 5,7 anos). O retorno à escola era desejado por todas, apesar das evasões escolares anteriores.

Estudei até a terceira, mas eu já fui para a escola sabendo ler e tudo. Eu já fiz a quarta série umas quatro vezes... Eu ia, me internava num lugar, fazia a quarta série. Saía no meio do ano... Depois, colocavam eu no abrigo de novo... E da escola eu vazava. Nisso foi passando o tempo... A burrona aqui, ó! Não sabe nem escrever! (E7, 15 anos).

A Tabela abaixo apresenta a caracterização das participantes por idade, razões para deixar a casa, tempo de vida na rua, tipo de violência como a doméstica e o estupro, tempo de envolvimento com a prostituição, escolaridade, drogas e tempo de uso, e resultado dos exames laboratoriais.

Dados sócio-demográficos das adolescentes entrevistadas (n=7). Dez 2003 - Jan 2004

\begin{tabular}{|c|c|c|c|c|c|c|c|c|}
\hline & $\begin{array}{l}\text { Idade } \\
\text { referida }\end{array}$ & $\begin{array}{l}\text { Tempo } \\
\text { na rua }\end{array}$ & $\begin{array}{l}\text { Razões para } \\
\text { deixar a casa }\end{array}$ & $\begin{array}{c}\text { Tempo de } \\
\text { prostituição }\end{array}$ & $\begin{array}{l}\text { Escola- } \\
\text { ridade }\end{array}$ & Gravidez & $\begin{array}{c}\text { Tempo } \\
\text { Droga } \\
\text { de uso }\end{array}$ & Testes positivos \\
\hline 1 & 16 anos & 7 anos & $\begin{array}{l}\text { Violência física } \\
\text { pelos irmãos }\end{array}$ & 3 anos & $4^{\mathrm{a}}$ série & & $\begin{array}{l}7 \text { anos } \\
\text { Crack } \\
\text { Cigarro } \\
\text { Solvente }\end{array}$ & $\begin{array}{l}\text { Sífilis } \\
\text { (não tratada) } \\
\text { HIV Indeterminado } \\
\text { Elisa e Imunofluo- } \\
\text { rescência }\end{array}$ \\
\hline 2 & 16 anos & 3 anos & $\begin{array}{l}\text { Violência física } \\
\text { pela mãe } \\
\text { Estupro aos } 12 \\
\text { anos por conhe- } \\
\text { cido }\end{array}$ & 3 anos & $7^{\text {a }}$ série & & $\begin{array}{l}2 \text { anos } \\
\text { Crack } \\
\text { Cigarro } \\
\text { Maconha }\end{array}$ & $\begin{array}{l}\text { Sífilis } \\
\text { (não tratada) } \\
\text { HIV + } \\
\text { Elisa eImunofluo- } \\
\text { rescência }\end{array}$ \\
\hline 3 & 18 anos & 3 anos & $\begin{array}{l}\text { Estupro com } \\
15 \text { anos por des- } \\
\text { conhecido }\end{array}$ & 3 anos & $8^{a}$ série & & $\begin{array}{l}3 \text { anos } \\
\text { Crack } \\
\text { Álcool } \\
\text { Cigarro } \\
\text { Maconha }\end{array}$ & $\begin{array}{l}\text { Sífilis } \\
\text { (não tratada) }\end{array}$ \\
\hline 4 & 18 anos & 3 anos & $\begin{array}{l}\text { Violência física } \\
\text { pela mãe } \\
\text { Estupro com } 16 \\
\text { anos por desco- } \\
\text { nhecido }\end{array}$ & 2 anos & $6^{\mathrm{a}}$ série & $\begin{array}{l}1 \\
(3 \text { anos }) \\
\text { Gravidez de } \\
6 \text { meses }\end{array}$ & $\begin{array}{l}2 \text { anos } \\
\text { Crack } \\
\text { Cigarro }\end{array}$ & \\
\hline 5 & 17 anos & 4 anos & $\begin{array}{l}\text { Violência física } \\
\text { pelos irmãos }\end{array}$ & 3 anos & $7^{a}$ série & $\begin{array}{l}1 \\
(2 \text { anos })\end{array}$ & $\begin{array}{l}4 \text { anos } \\
\text { Crack } \\
\text { Álcool } \\
\text { Cigarro }\end{array}$ & $\begin{array}{l}\text { Sífilis } \\
\text { (tratada) }\end{array}$ \\
\hline
\end{tabular}




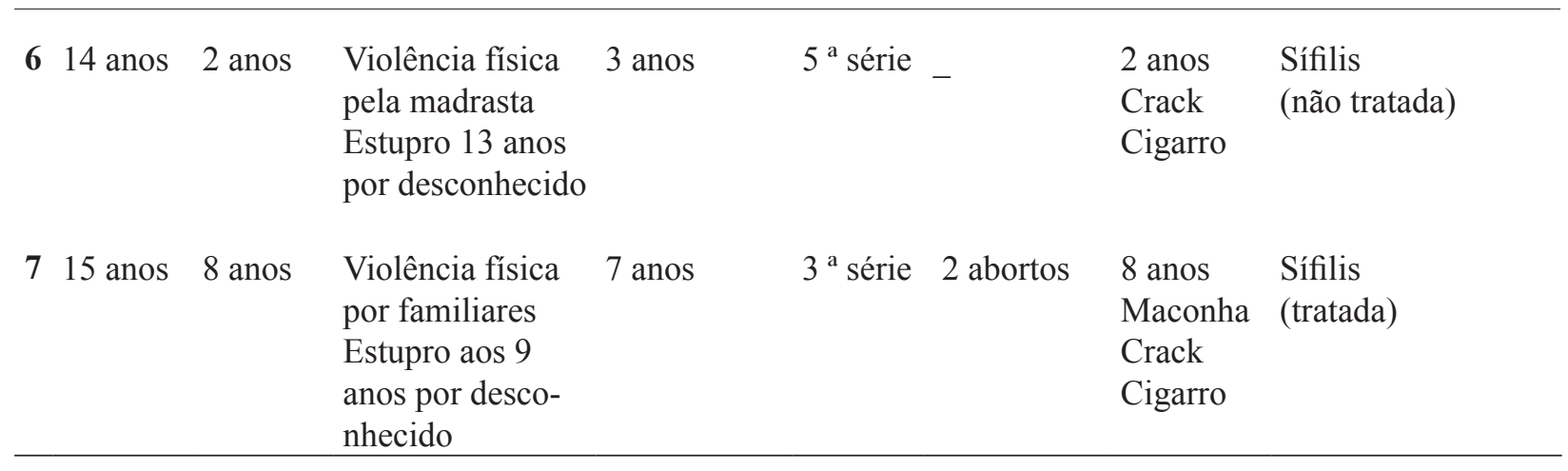

\section{Violência doméstica}

As adolescentes abandonaram a família entre 12 e 16 anos, com exceção de uma, que o fez aos sete anos.

As minhas irmãs não gostam de mim; elas querem ver o meu mal, sabia? Tudo o que há de ruim as minhas irmãs socam para dentro de mim... Eu já fumava cigarro desde cinco anos de idade. Minha avó descobriu e quebrou este dente meu (E7, 15 anos).

Eu me lembro até hoje disso... Eu tinha muito medo de apanhar. Por causa que a minha tia disse assim, que um dia, se a gente saísse de casa de novo... Não voltava mais... E muito menos com uma barriga... (E5, 17 anos).

A violência foi apontada como fator impeditivo para o retorno à família, ainda que manifestassem o desejo de voltar: "Eu saí por causa de maus tratos... As vezes, ela me batia para machucar mesmo... Ainda ela me bate... Eu saía... Ia usar droga... Ia e voltava... E depois que fui estuprada não voltei mais morar lá..." (E4, 18 anos).

\section{Violência na Rua}

As adolescentes relataram vários episódios de violência com os clientes, como o espancamento:

Foi por um cara, tia... Teve motivo... Foi porque eu não queria transar com ele. Ele foi lá e me espancou. Ele me espancou tanto que eu cheguei até a desmaiar. Ai... Quando eu acordei... Ele saiu correndo... Ai eu sai de dentro do terreno... A gente fica com medo, não é tia? (E6, 14 anos).

Quatro delas referiram ter sido vítimas de estupro: "Foi no dia do meu aniversário que eu fiz quinze anos. Logo que eu comecei a usar drogas... Foi um cara de um caminhão. Não contei para ninguém... Ficou para mim" (E3, 18 anos); "Era um cara de caminhão. Mas naquela época... Quando eu tinha dezessete anos... Eu usava só maconha, não usava pedra... Depois eu fiquei entrando na neurose... Ai eu conheci uma colega minha e ela me ofereceu..." (E4, 18 anos).
Relataram, também, episódios de ferimento por arma de fogo, que foram devidamente atendidos e notificados (boletim de ocorrência - BO) na urgência do centro hospitalar.

Ele mostrou o revólver e falou assim: entra no carro. Eu falei, eu não vou entrar no seu carro. Nisso, eu reagi. Ele rodopiou o carro, pegou a arma e eu estava encostada no poste... E ele, atrás do carro, atirou. Foi isso que aconteceu. (E5, 17 anos).

\section{A vida na prostituição}

As adolescentes viviam na rua e envolvidas com a prostituição há pelo menos dois anos. A idade do início variou dos sete aos dezesseis anos. Diferiam das outras mais velhas, com quem dividiam o espaço da rua, sobretudo pela aparência descuidada, trajes sumários e por cobrar menos. Contaram que haviam sido estimuladas por pessoas próximas e encontraram nas companheiras da rua uma referência e um modelo. Mantinham, em média, cinco relações sexuais por noite, cobrando de $\mathrm{R} \$ 10,00$ (dez reais) a $\mathrm{R} \$ 20,00$ (vinte reais): "Eu fui aprendendo... Eu via elas fazendo, olhava e fazia... Elas estavam lá na casa de acolhida e são as das antigas na Avenida Industrial, junto com os travestis..." (E3, 18 anos).

\section{A prostituição e uso de drogas}

Todas referiram uso de múltiplas drogas diariamente (álcool, tabaco, maconha e crack), há pelo menos dois anos, sendo o crack a droga de escolha e uso compulsivo (quatro ou mais pedras por dia). O dinheiro proveniente do comércio sexual era empregado por todas quase exclusivamente no consumo de crack.

O que eu faço, entendeu... Não vou falar que não dá dinheiro. Tanto que se eu não usasse droga, eu tinha... Quatro anos gastando tanto dinheiro que eu já peguei nos meus programas... Todo o dinheiro que eu pego é na maldita. Todo! (E3, 18 anos).

Mencionaram que as drogas fazem parte da vida na rua: “Ah, eu fico na nóia, fico assim, pá, pum... Não fico pensando no meu sentimento... O que está me machucando..." (E7, 15 anos). 


\section{Os relacionamentos e o ideário das DST/AIDS}

As participantes referiram ter conhecimento sobre as DST/AIDS e o uso de preservativos para a prevenção, porém, na prática, não os adotavam com os clientes fixos ou com os namorados: "Não, não acho que eles têm doença... A maioria é casado... E eles não traem muito... Eles traem assim... Mas respeitam... Tem uns que falam que se arrependem até de sair com outras, de trair a mulher..." (E1, 16 anos).

Acreditavam que seus relacionamentos amorosos eram imunes às DST/AIDS: "Quando saio sempre uso preservativo... Eu só não uso com uma pessoa só... Porque nós já temos um caso bem antigo... Ele é casado e é um pai de familia..." (E3, 18 anos).

\section{A gravidez e o desejo de filhos}

Duas adolescentes tiveram suas primogênitas com idade aproximada de quinze anos. Uma delas, durante a realização da entrevista, estava no sexto mês de sua segunda gravidez e teve o bebê prematuro, em um hotel, durante um programa, cerca de um mês após a entrevista. Revelaram que não fizeram acompanhamento prénatal por medo de serem descobertas e internadas.

Eu tinha... Quando conheci meu lindo, meu amor, eu tinha treze anos... Meu marido hoje tem 42 anos, meu ex-marido... Eu tenho uma filha de dois anos... Fui eu que sai de casa... Se eu bater o pé e dizer que eu vou lá ver, vou e vejo. Mas eu sou uma drogada, vou lá, minha filha se apega e eu vou levar ela? Eu vou querer a minha vida para ela? Nunca. Por isso que hoje eu entendo o que minha tia fazia com a gente, ela batia... Ela não queria que gente fosse empregada doméstica como ela porque ela não ouvia os pais dela, como eu... (E5-17 anos).

A gravidez e o desejo de ter filhos aparecem frequentemente em seus relatos, e surgem como um forte motivo para evitar o uso de preservativo nessas relações afetivas: "Quando eu fiz quinze engravidei de novo... Ai eu perdi... Ah, mas agora, se eu tentar engravidar, eu não consigo... Ah, eu quero ter um nenê. Agora, não estou nem aí..." (E7, 15 anos).

As crianças nascidas foram recolhidas pelo Conselho Tutelar e estão sendo cuidadas por pessoas da família (ex-marido e mãe), mas, apesar de próximas, as jovens não têm mais contato com seus filhos por imposição das famílias, fato narrados com grande sofrimento:

Eu gostaria de sempre estar ao lado da minha filha, criar ela... Se eu arrumar um cara que sustente eu e minha filha, eu paro de usar droga. Mas tipo assim... Quem me quer é só usuário, ai num vira... (E4,18 anos).

\section{Expectativas de futuro}

Todas expressavam vontade de sair da rua, não utilizar drogas, casar, ter filhos, estudar e trabalhar: " $E u$ quero arrumar um serviço bom e terminar de estudar" (E2,16 anos).

Durante a entrevista, revelaram o que pensavam: "Mudar de vida. Eu queria mudar de vida... Não é? Sei lá, é um passo longo..." (E3,18 anos).

Elas não acreditavam que conseguiriam mudar de vida, e achavam que ninguém se preocupava com elas: "Se eu pudesse voltar na máquina do tempo, do começo, meu... Eu não ia nem nascer... Porque ninguém merece. Vai nascer para ficar assim?" (E7,15 anos).

\section{Resultados de exames}

O teste para sífilis foi positivo em seis adolescentes. Apenas duas haviam sido tratadas, devido à internação por outros motivos - uma após ter sido baleada no abdome (E5) e outra por febre alta e tosse (E7). O teste para HIV foi positivo em uma adolescente (E2) e indeterminado em outra (E1), sendo que ambas mantinham contato sexual sem proteção com o mesmo parceiro fixo.

Propôs-se às entrevistadas seguimento ambulatorial pelo serviço de referência do programa de DST/ AIDS (COAS). Apenas uma (E2) concordou em ser acompanhada até a primeira consulta clínica. As demais alegaram dificuldade em comparecer à consulta no horário pré-agendado, durante a manhã.

\section{Discussão}

As adolescentes relataram que o principal motivo que as levou à rua foi a violência doméstica, agravada pela precária situação socioeconômica de suas famílias, caracterizando uma exclusão socioeconômica (da escola, do consumo, do mercado de trabalho, da saúde e da cultura).

Uma vez vivendo na rua em condições de pobreza, o envolvimento com pessoas ou redes que delas se utilizam para a exploração sexual comercial ou para o consumo ou tráfico de drogas é uma possibilidade muito frequente (Adorno, 1998; Gomes, 1994; Leal, 1999; Minayo \& Souza, 2003). Assim, essa tentativa de organização e construção de uma forma peculiar de vida na rua, fora da violência de casa, pode se tornar definitiva, e a ruptura dos laços afetivos com seus familiares, por sua vez, podem as tornar mais vulneráveis a outros episódios de violência (Coid, Petruckevitch, Feder, Chung, Richardson, \& Moorey, 2001) e, sobretudo, às DST/AIDS (Rafaelli et al., 1993; Taquette, Ruzany, Meirelles, \& Ricardo, 2003; Noto et al., 2004). 
Observamos que as adolescentes entrevistadas vivenciaram outras formas de violência além da doméstica (agressões físicas, estupro, entre outras). Além de vítimas da violência estrutural, caracterizada pela falta de condições mínimas de sobrevivência em suas famílias, da violência dentro e fora de casa, elas se tornaram vítimas também da exploração sexual comercial, ainda que, para elas, a venda do corpo seja apenas uma entre inúmeras estratégias de sobrevivência para atender às necessidades básicas, conforme relatado por Greene, Ennet e Ringhwalt (1999).

Uma vez na rua, o binômio drogas e prostituição apresenta-se como a nova referência, ou melhor, como um enunciado que caracteriza as relações nesse novo ambiente. $\mathrm{O}$ uso de drogas e a comercialização do próprio corpo estão estreitamente ligados, na medida em que o primeiro termo possibilita a entrega do corpo como mercadoria, isentando o sujeito de um aprofundamento reflexivo quanto ao que está entregando ao pagador. No entanto, para que possa desfrutar desse eficaz anestésico, necessita do pagamento que esse ato de comércio envolve, engendrando-se, assim, um ciclo que se retroalimenta, conforme relata E3.

A droga, elemento estrutural no relato dessas adolescentes, impõe-se por seu efeito medicamentoso: poder aguentar os imperativos que determinam de forma não só violenta, mas também trágica, a vida na rua sustentada pelo consumo do próprio corpo, como relata E7.

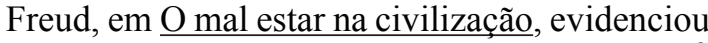
o elemento trágico que marca a existência humana. É universal, para os seres falantes, a experiência de um estado no qual as garantias sobre a manutenção da própria vida ficam reduzidas às simples condições do acaso:

O sofrimento nos ameaça a partir de três direções: de nosso próprio corpo, condenado à decadência e à dissolução ...; do mundo externo, que pode voltar-se contra nós com forças de destruição esmagadoras e impiedosas; e, finalmente, de nossos relacionamentos com os outros homens (1929/1974, p. 95).

Uma das possibilidades de atenuar essa condição de profundo desamparo citada pelo autor é através da intoxicação química. Ainda que seja uma forma grosseira, revela-se relativamente eficaz, no sentido de amortecer as preocupações da vida que sempre têm como pano de fundo a consciência sobre o estado de abandono à própria sorte, que constitui o elemento mais concreto da experiência humana.

Além do abuso sexual e a exploração comercial, entendida como uma relação de dominação e de violação dos Direitos Humanos, como por exemplo: de se desenvolverem com saúde, como salienta Gomes (1994), essas adolescentes estão igualmente submetidas à violação do direito ao trabalho e em condições dignas (Faleiros \& Campos, 2000), pois a prostituição garante a essas adolescentes uma forma de renda e subsistência, dentro de um mercado capitalista.

Esses aspectos instigam a reflexão concernente à condição de ter um corpo, tal como foi enfatizada por Lacan: "ter um corpo é poder fazer alguma coisa com..." (2003, p. 562).

Tendo em vista os fenômenos aqui abordados, como prostituição e abuso de drogas, a apropriação do corpo assume contornos específicos, na medida em que ele é sobre utilizado, ou melhor, superfaturado. Nesse contexto, o corpo constitui, ao mesmo tempo, meio para ofertar prazer ao outro, recurso de sobrevivência e instrumento para proporcionar uma experiência transcendental, uma vez que é pelo corpo que a droga penetra no sujeito.

$\mathrm{O}$ desejo de encontrar um parceiro amoroso entre os homens disponíveis e o desejo de engravidar impedem a negociação do uso de preservativos com os mesmos.

Isso nos leva a pensar que essas adolescentes buscam, ainda que no contexto da rua, uma identidade feminina expressa no desejo de ter um bebê de um parceiro previamente escolhido, o que pode ser equiparado à busca de um atributo fálico em uma das formas que poderiam levá-las a um apaziguamento concernente à própria relação com a feminilidade. Vemos que, nas adolescentes entrevistadas, a vontade de ter um filho se dá em condições diferenciadas, segundo os apetites subjetivos. E5, por exemplo, enfatizava a idade do pai de sua filha: um homem bem mais velho. É interessante observar, nesse relato, a insuficiência da maternidade e da parceria amorosa para o rompimento com a vida na rua e com as drogas. A sentença "eu sou drogada" impõe-se relativamente ao reconhecimento de ser mãe.

Vemos que E7 fala abertamente sobre a dificuldade de viver nas condições tanto de miséria física como psíquica, sobre o uso de múltiplas drogas, principalmente o crack, o desamparo atual e também o desejo de construir uma família com o namorado, a partir de uma gravidez.

A descoberta da sexualidade entre as adolescentes que fazem das ruas seu espaço de sobrevivência geralmente é permeada pelo desconhecimento do próprio corpo, o que resulta, muitas vezes, em uma gravidez que, contudo, pode ter um significado positivo.

As crenças na imunidade às DST/AIDS e a desesperança quanto ao futuro, presentes no discurso dessas adolescentes, são aspectos que também dificultam a realização de programas de saúde. Contudo, a experiência da maternidade pode significar uma oportunidade para o estabelecimento de novas formas de estar e relacionar-se no mundo, sendo o processo de construção da identidade, a partir dessa nova significação, uma forma saudável de formar ou resgatar 
seus próprios valores, se conseguirem o suporte de uma equipe psicossocial que possa garantir essa passagem (Gontijo \& Medeiros, 2008).

Os modelos preventivos para esse fenômeno complexo composto pela situação de rua, a prostituição, as drogas e DST/AIDS, assim como a gravidez precoce, para serem efetivos, requerem o entendimento do conceito de vulnerabilidade como o somatório de todos esses fatores associados à idade, ao gênero e ao nível sócio-econômico.

As estratégias com adolescentes, centradas em promover o sexo protegido, devem levar em conta a condição de cada uma como sujeito desejante, em busca de um lugar na sociedade, ainda que em condições consideradas adversas, e oferecer um espaço de escuta e acolhimento (Pantoja, 2003).

Aqueles modelos centrados exclusivamente na informação e na abstinência se mostram ineficientes, pois não levam em conta o sujeito e suas crenças, estas centrais para a mudança de atitude e o engajamento em qualquer atividade idealizada, como o sexo protegido e o autocuidado (Paiva, Peres, \& Blessa, 2002).

Assim, como salienta Ayres, França-Junior, Calazans e Saletti Filho (2003), devemos considerar as possibilidades de exposição das pessoas ao adoecimento como resultantes de um conjunto de aspectos não apenas individuais, mas também coletivos, contextuais e programáticos ou institucionais, que acarretam maior suscetibilidade, exigindo estratégias específicas aplicáveis e uma resposta social advinda principalmente das políticas de Saúde Pública, tanto por sua gravidade quanto por seu alto custo individual e social. Desse modo, a intervenção institucional torna-se necessária para permitir o acesso à escolarização, aos meios de informação e comunicação, e o enfrentamento das barreiras culturais e socioeconômicas. Para isso, faz-se necessária uma diretriz unificada em toda a rede, tanto nos diversos programas existentes como na criação de novos serviços, para que essas adolescentes possam ser atendidas integralmente, deixando-se de enfocar apenas uma de suas necessidades como, por exemplo, o tratamento do abuso de drogas.

A rede psicossocial na cidade, durante o período da pesquisa, apresentava um momento de descontinuidade nos serviços prestados, como a falta de abrigo apropriado para a idade e a falta de profissionais preparados para o atendimento dessas adolescentes nos serviços especializados na rede de atenção psicossocial, bem como de educadores sociais de rua. Portanto, além da necessidade de que os serviços garantam acesso aos seus usuários, promovendo o ingresso e a estadia pelo maior número de horas possível tanto em escolas inclusivas, centros comunitários e oficinas de trabalho, é vital a continuidade dos serviços prestados e o treinamento do pessoal envolvido (De Carvalho et al., 2006; Noto et al., 2004).

Os programas específicos de prevenção às DST/ AIDS, como o de Redução de Danos ao uso de drogas - PRD, juntamente com os educadores sociais de rua e agentes comunitários do programa de saúde de família - PSF, por terem como um dos pilares o trabalho de campo, poderiam realizar a busca ativa das envolvidas que se encontram totalmente excluídas e, também, acompanhar o projeto terapêutico adequado para cada uma, nos diversos equipamentos da rede, além de prepará-las para serem agentes multiplicadoras de saúde, para uma efetiva e necessária educação entre pares (Ayres, Freitas, Santos, Saletti Filho, \& França-Junior, 2003).

A distribuição de folhetos informativos e a oferta de preservativos pelos PRD constituem apenas ferramentas para o primeiro contato. Norteados pelo projeto terapêutico de cada adolescente, pode-se assim conquistar um espaço de escuta desde essa primeira aproximação, permitindo-lhes a construção de outras representações sobre a sua própria vida, além das vivenciadas na rua. É importante considerar que essas adolescentes devem desde o início ser tratadas como adolescentes, e não sob o caráter de profissionais do sexo, para que a sua identificação não seja cristalizada nessa situação e que possa caminhar para a independência econômica e emancipação.

Freire (1975) já alertava sobre a necessidade da busca de autonomia, pois as pessoas são portadoras de uma cultura e historicidade e proprietárias de seu destino, e não vasilhas a serem cheias de informação.

Como não se trata de uma amostra probabilística, os achados revelam a realidade encontrada nesse contexto sócio-histórico. Porém, como essas adolescentes vivem um processo de exclusão semelhante ao que ocorre em bolsões de pobreza de outros locais, podem propor algumas reflexões necessárias para novas pesquisas com adolescentes vulneráveis, para que medidas sócio-educativas e estratégias preventivas de saúde possam estar em sintonia com o ideário e a necessidade de cada adolescente envolvida.

\section{Considerações Finais}

O baixo nível socioeconômico das famílias e a violência dentro do lar podem provocar a ruptura dos laços familiares. A baixa escolaridade e o abuso de drogas lícitas e ilícitas influem de modo marcante na permanência das adolescentes na rua. Associados a outros fatores, como a necessidade de sobreviver financeiramente, esses elementos facilitaram a crescente exploração sexual infanto-juvenil.

As necessidades afetivas, em conjunto com a demanda do mercado do sexo remunerado, contribuem 
para a vulnerabilidade às DST/AIDS, pois, mesmo conhecedoras da necessidade de proteção durante o ato sexual, as adolescentes não o fazem, seja por imposição do parceiro, seja pela busca de afetividade nos relacionamentos.

As histórias relatadas pelas adolescentes nos permitem concluir acerca da vulnerabilidade atual e da necessidade de programas específicos que facilitem sua adesão e permanência no tratamento, com horários acessíveis, baixo umbral de exigências, atendendo às necessidades psicossociais e culturais de cada uma.

\section{Referências bibliográficas}

Adorno, R. (1998). Os imponderáveis circuitos dos vulneráveis cidadãos: trajetórias de crianças e jovens das classes populares. In J. Lerner (Coord.), Cidadania, verso e reverso (pp. 93-109). São Paulo: Imprensa Oficial do Estado.

Angrimani, D. (2003, 6 de julho). Meninas se prostituem por drogas. Diário do Grande $A B C$, p.1.

Ayres, J. C. R. M., França-Junior, I., Calazans, G. J., \& Saletti Filho, H. C. (2003). O conceito de vulnerabilidade e as práticas de saúde: novas perspectivas e desafios. In D. Czeresnia \& C. M. Freitas (Orgs.), Promoção da saúde: Conceitos, reflexões e tendências (pp. 117-140). Rio de Janeiro: Fiocruz.

Ayres, J. C. R. M., Freitas, A. C., Santos, M. A. S., Saletti Filho, H. C., \& França-Junior, I. (2003). Adolescência e AIDS: avaliação de uma experiência de educação preventiva entre pares. Interface Comunicação, Saúde \& Educação, 7, 123-138.

Bardin, L. (1977). Análise de conteúdo ( $3^{\mathrm{a}}$ ed.). Lisboa: Edições 70.

Bonomo, Y. \& Bowes, G. (2001). Putting harm reduction into an adolescent context. Journal of Paediatrics \& Child Health, 37(1), 5-8.

Brasil. (1990). Lei n. 8.069, de 13 de julho de 1990. Dispõe sobre o Estatuto da Criança e do Adolescente-ECA. Retirado em maio 2003 de http://www.planalto.gov.br/ccivil/LEIS/ L8069Compilado.htm

Brasil. Ministério da Saúde. (2005, janeiro/junho). Boletim Epidemiológico AIDS/DST, II(1). Brasília, DF: Autor. Acesso em janeiro, 2006, em http://www.aids.gov.br

Brasil. Ministério da Saúde. (2006, janeiro/junho). Boletim Epidemiológico AIDS/DST, III(1). Brasília, DF: Autor. Acesso em janeiro, 2007, em http://www.aids.gov.br

Brasil. Ministério da Saúde. (2007, janeiro/junho). Boletim Epidemiológico AIDS/DST, IV(1). Brasília, DF: Autor. Acesso em janeiro, 2008, em http://www.aids.gov.br

Brito, A. M., Castilho, E. A., \& Szwarcwald, C. L. (2000). AIDS e infecção pelo HIV no Brasil: uma epidemia multifacetada. Revista da Sociedade Brasileira de Medicina Tropical, 34(2), 207-217.

Coid, J., Petruckevitch, A., Feder, G., Chung, W. S., Richardson, J., \& Moorey, S. (2001). Relation between childhood sexual and physical abuse and risk of revictimisation in women: a cross-sectional survey. Lancet, 358, 450-454.

Comunidade Européia.(2008). Livro Azul 2008 - Cooperação da União Européia no Brasil. R1-P12-98 - Diminuição dos danos nas mulheres dependentes e/ou co-adictas. Acesso em setembro, 2008, em http://www.delbra.ec.europa.eu/pt/downloads/ book\%20livro\%20azul\%202008\%20portugues.pdf
De Carvalho, F. T., Neiva-Silva, L., Ramos, M. C. J., Koller S. H., \& Page Shafer, K. (2006). Sexual and drug use risk behaviors among children and youth in street circumstances in Porto Alegre, Brazil. Aids and Behavior, 10, 57- 66.

Faleiros, E. T. S. \& Campos, J. O. (2000). Repensando os conceitos de violência, abuso e exploração sexual de crianças e adolescentes. Brasília: Thesaurus.

Freire, P. (1975). Pedagogia do oprimido. Rio de Janeiro: Paz e Terra.

Freud, S. (1974). O Mal-estar na cultura e na civilização e outros trabalhos. In Edição standard brasileira das obras psicológicas completas (Vol. 21, pp. 81-178). Rio de Janeiro: Imago. (Original publicado em 1929).

Gomes, R. (1994). A violência enquanto agravo à saúde de meninas que vivem nas ruas. Caderno de Saúde Pública, 10(1), 157-167.

Gomes, R. (1996). O corpo na rua e o corpo da rua: a prostituição infantil feminina em questão. São Paulo: Unimarco.

Gontijo, D. T. \& Medeiros, M. (2008). “Tava morta e revivi”: significado de maternidade para adolescentes com experiência de vida nas ruas. Caderno de Saúde Pública, 24(2), 469-472.

Greene, J. M., Ennet, S. T., \& Ringhwalt, C. (1999). Prevalence and correlates of survival sex among runaway and homeless youth. American Journal Public Health, 89(9), 406-409.

Joint United Nations Programme on HIV/AIDS. (2008). Latin America: AIDS epidemic update: regional summary. Geneva: WHO Library Cataloguing-in-Publication Data. Acesso em janeiro, 2008, em http://data.unaids.org/pub/Report/2008/ jc1530_epibriefs_latinamerica_en.pdf

Krug, E. G., Fdahlberg, L. L., Mercy, J. A., Zwi, A. B., \& Lozano, R. (2002). Word report on violence and health. Geneva: Word Health Organization.

Lacan, J. (2003). Outros escritos. Rio de Janeiro: Jorge Zahar Editor. Leal, M. L. P. (1999). A exploração sexual comercial de meninos, meninas e adolescentes na América Latina e Caribe. (Relatório Final - Brasil). Brasília: CECRIA.

Minayo, M. C. S. (1994). O desafio do conhecimento: pesquisa qualitativa em saúde. Rio de Janeiro: Hucitec.

Minayo, M. C. S. \& Souza, E. R. (Orgs.). (2003). Violência sobre o olhar da saúde: a infrapolitica da contemporaneidade brasileira. Rio de Janeiro: Fio Cruz.

Moura, S. L., Harpham, T., \& Lyons, M. (2003). The social distribution of explanations of health and illness among adolescents in São Paulo, Brazil. Journal of Adolescence, 26, 459-473.

Nappo, S. A., Sanchez, Z. M., Oliveira, L. G., Santos, S. A., Coradete Jr, J., Pacca, J. C. B., \& Lacks, V. (2004). Comportamento de risco de mulheres usuárias de crack em relação às DST/AIDS. São Paulo: CLR Balieiro.

Noto, A. R., Galduroz, J. C., Nappo, S. A., Fonseca, A. M., Carlini, M. A., Moura, Y. G., \& Carlini, E. L. A. (2004). Levantamento nacional sobre uso de drogas entre crianças e adolescentes em situação de rua nas 27 capitais brasileiras - 2003. São Paulo: CEBRID.

Paiva, V., Peres, C., \& Blessa, C. (2002). Jovens e adolescentes em tempos de AIDS: reflexões sobre uma década de trabalho de prevenção. Psicologia USP, 13(1), 55-78.

Paludo, S. S. \& Koller, S. H. (2005). Resiliência na rua: um estudo de caso. Psicologia Teoria \& Pesquisa, 21(2), 187-195.

Pantoja, A. L. N. (2003). "Ser alguém na vida": uma análise sócio-antropológica da gravidez/maternidade na adolescência, em Belém do Pará, Brasil. Caderno de Saúde Pública, 19, 335-343. 
Pinheiro, P. S. (2006). Violence against children: United Nation Secretary-General's Study. Acesso em 17 de janeiro, 2007, em http://www.unviolencestudy.org

Raffaelli, M., Campos, R. A., Merritt, P., Siqueira, E., Antunes, C. M., Parker, R., Grego, D., Halsey, N., \& The Street Youth Study Group (1993). Sexual practices and atitudes on street youth in Belo Horizonte, Brazil. Social Science \& Medicine, 7, 661-670

Silva, E. R. (2004). O direito à convivência familiar e comunitária: os abrigos para crianças e adolescentes no Brasil. Brasília: IPEA/CONANDA.

Simon, C. P. (1999). Prostituição juvenil feminina: uma abordagem compreensiva. Dissertação de Mestrado, Faculdade de Medicina, Universidade de São Paulo, Ribeirão Preto, SP.

Spink, M. J. (2000). Práticas discursivas e produção de sentidos no cotidiano: aproximações teóricas e metodológicas. São Paulo: Cortez.

Taquette, S. R., Ruzany, M. H., Meirelles, Z., \& Ricardo, I. (2003). Relacionamento violento na adolescência e risco de DST/AIDS. Cadernos de Saúde Pública, 19, 1437-1444.

Eliane Lima Guerra Nunes é Professora colaboradora da Disciplina de Psicologia Médica e Psiquiatria da Faculdade de Medicina do ABC. Doutora em Ciências pela Faculdade de Medicina da Universidade de São Paulo-USP.

Endereço para correspondência: Av. Lauro Gomes, 2000.

Vila Sacadura Cabral - Santo André - São Paulo. CEP. 09060-870.

E-mail: elianeguerranunes@yahoo.com.br

Arthur Guerra de Andrade é Professor Titular da Disciplina de Psicologia Médica e Psiquiatria da Faculdade de

Medicina do ABC. Médico, com Residência em Psiquiatria no Instituto de Psiquiatria do Hospital das Clínicas da Faculdade de Medicina da USP (1981). Doutorado pela FMUSP e Pós-doutorado (1992). Fundador e Presidente Executivo da ONG CISA, Centro de Informações Sobre

Álcool, desde 2004.

Email: arthur_guerra@uol.com.br

\section{Adolescentes em situação de rua: prostituição, drogas e HIV/AIDS em Santo André, Brasil}

Eliane Lima Guerra Nunes e Arthur Guerra de Andrade

Recebido: 01/10/2007

$1^{\text {a }}$. Revisão: $28 / 01 / 2008$

Aceite final: 31/07/2008 